\section{I.-Sulphocarbolates of Alkaline Bases.}

Of these the sodium, potassium, and ammonium salts have been obtained. In testing their therapeutical characters, I have confined myself, for the sake of uniformity, to the sodium salt. The dose has been usually twenty to thirty grains three times a day to adults, though I have given as much as a drachm every four hours. At the North-Eastern Hospital for Children, I have had abundant opportunities of testing the action of this salt in diseases of children. The patients coming from the most impoverished quarters of London, there are numerous examples of the various conditions of wasting disease. In cases of thrush, I have found the oiddium-growth to pass away much more quickly during the administration of sulphocarbolate of sodium than under any other plan of treatment, the sulphites not excepted. There has been during the present year a great prevalence of stomatitis - the occurrence of small circular ulcerations upon the tongue, gums, and internal surface of the cheeks. I have noticed a very strong relation subsisting between this condition and diarrhœe. In the diarrhœea which prevails at the present time, I have, on close inspection of the mouth, been able to detect in numerous instances cicatrices indicating that a condition of stomatitis has existed unnoticed. This fact may, I think, be of subsequent importance with reference to the consideration of the causation of diarrhœea. This condition of stomatitis has invariably, under the sulphocarbolate, disappeared from the third to the seventh day of treatment.

Follicular Inflammation and Ulccration of Tonsils. - I have administered the sulphocarbolate in eleven such cases, with the result of complete recovery in one case on the third day ; in eight cases on the fourth day ; two were not observed till the seventh day-they were then quite well. Several of these cases had previously had the same affection going its course to suppurative tonsillitis-in none of them was there a trace of suppuration. I should add that they were all cases accompanied by severe pyrexia.

Sloughing Ulceration.--In three cases of great severity, accompanied by diphtheritic signs, there was complete recovery without complications. Convalescence took place in one case on the seventh day; in another, wherein the thermometer had registered 106 degrees Fahr., the child was able to walk on the fourteenth day; in the third, with severe pyrexia (temperature I05 degrees Fahr.), delirium, and large ashy slough over each tonsil, perfect power of swallowing returned on the sixth day, and progress was uninterrupted.

Scarlatina. - In eighteen cases in which the sulphocarbolate was administered, recovery was very rapid. The throat-signs became rapidly alleviated; it was an almost invariable rule that, at the end of the fourth day of treatment, all throat-distress had passed away. It should be added, that in all these cases not any local treatment to the throat whatever was practised, nor any other remedy save the sulphocarbolate. The pyrexia rapidly diminished. Cumplete convalescence took place in six cases in seven days; in one, in eleven; in one, in fourteen; in one, in fifteen days. The sequelæ were, in one case general anasarca resulting in recovery; in one, albuminuria for a single day; in one, abscess of a superficial gland in the neck; and, in one, a persistent slight glandular swelling.

Variola.-My experience of the remedy in this affection is very limited; but I think it is sufficient to induce an extended trial. I have used it in two cases; one of these was a gentleman of middle age, who made an excellent recovery. He had, however, been vaccinated, so the result could have but little weight. I have since, however, had a severe case in a child of one year and eight months, unvaccinated. The progress was uninterrupted, the pitting very slight, and complete convalescence took place at the end of the fourth week. In none of the zymotic cases thus treated did a death occur.

Enteric Fever. - I have not myself had any opportunity of using the sulphocarbolates in this disease. Dr. Ligertwood, of Newbury, has, however, put the plan in practice, and has forwarded me a tabular statement of twenty-four cases so treated. Dr. Ligertwood says : "I think the treatment was very successful. There did not seem to be the same tendency to relapse that $I$ have found occur under other treatment. The diarrhcea, often very severe, never jecame so exhausting as to call for any special treatment, and the average duration of the fever was certainly not more than under the usual modes of treatment."

Tuberculosis. - In testing the therapeutic effects of sulphocarbolate of sodium upon phthisical patients at the Chest Hospital, where I first begun to employ it, I was so struck with the signs of general improvement that $I$ determined to give it an extended trial in these cases. It must be remembered, however, that in most cases cod-liver oil was used in addition. In eleven cases of children showing signs of general tuberculosis, eight improved considerably; two seemed uninfluenced; and one went from bad to worse, the progress of tuberculisation being evidently unchecked. From notes of seventy-eight cases of pul- monary phthisis in which I employed it, the following are the results. First Stage: fifteen cases. In eleven much improvement, with marked decrease of symptoms and increase in nutrition. Second Stage: fifty-one cases. Thirty manifested much improvement; seven slight improvement ; twelve uninfluenced ; in two disease progressed rapidly. Thirel Stage: sixteen cases. Ten much improvement; twelve uninfluenced; in two disease progressed rapidly. I entirely leave the interpretation of these results.

\section{II.-Sulphocarbolates of the Alkaline Earths.}

The magnesizım salt crystallises in large clear rhombic prisms. One of the most interesting of the whole series is the calcinm salt. This is obtained in long, fine, delicate crystals, which, interlacing, somewhat resemble benzoic acid. It is exceedingly soluble; and this I consider to be a most valuable characteristic. The following expresses the solubility of calcium salts at $60 \mathrm{deg}$. Fahr.

\section{Calcium carbonate $\}$ insoluble.}

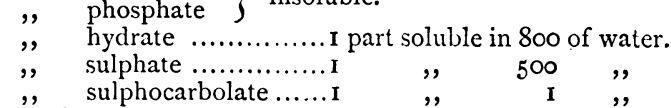

I thought that the calcium sulphocarbolate might prove useful in the treatment of rachitis. I accordingly employed it in twenty-six cases, with these results : great improvement in sixteen cases (of these there was, to all seeming, complete recovery in ten); moderate improvement in five; doubtful result in five.

In some of the cases cod-liver oil was administered in addition; but in many, in which there was the most marked improvement, the sulphocarbolate alone was given. The usual dose for children between the first and second year was five grains. I have also used the sulphocarbolate added to ordinary chalk-mixture in cases of chronic diarrhoea in unhealthy children, apparently with good result. Of the efficacy of the treatment in rachitic disease I think I am entitled to speak with some confidence.

\section{III.-Sulphocarbolates of the Metals.}

Of these I have obtained the iron, the copper, and the zinc salts, all of which present highly characteristic appearances. The zinc salt is in brilliant colourless right rhombic prisms; the copper salt possesses a blue colour, much resembling that of the sulphate. Mr. John Wood has employed these in lotions to prevent suppuration in wounds: he considers that they exercise an obvious control over the suppurative process. The only salt of the internal administration of which I have had any experience is the iron sulphocarbolate. This is a colourless very soluble salt, crystallising in rectangular plates. It assumes, in the presence of peroxide of iron, a deep mauve or purple tint. I employed it as a general tonic in diseases of debility in children; some cases of eczema and of impetigo became rapidly better under its influeuce, but I did not conclude that it was superior to the other salts of iron. In a case of enlarged and strumous giands, there was much amendment, and the swellings almost entirely disappeared. In ten cases of threatened tubercle there was considerable improvement in four; in the remainder it was doubtful. In cases of pulmonary tuberculosis there was much improvement in six cases; slight improvement in seven cases; no improvement in eight cases. I could state confidently that the results were not nearly so satisfactory as in the cases treated by the sodium salt.

In conclusion, I trust that these few imperfect observations will induce many of my professional brethren to test in actual practice the value of these interesting salts. Their place in therapeutics can in no sense be fixed by the experience of one indiviaual. As to their mode or action, there may be very many who widely differ from me in the opinions which I have enunciated ; but their physical characters alone will, I think, enable them to hold a useful place in our materia medica.

\section{CASES OF INHERITED PURPURA, OR HEREDI- TARY HÆMORRHAGIC DIATHESIS.}

\section{By FREDERICK WATERHOUSE, M.R.C.S., Pontypridd.}

In the JOURNAL of February 5 th last, I described a case showing the consequences of injury in subjects of a hæmorrhagic tendency; and it will no doubt be of interest, more especially to those working for the Jacksonian Prize, if I now record the subsequent history of the family in which that case occurred.

The mother has several times since suffered from intractable menorrhagia.

The boy, whom I have previously described, was again under treat: 
ment in June and July last. He had effusion around the ankle, which, although yielding to pressure, would not give the non-elastic pitting indicative of œdema, until the third day after its appearance. He could bear no weight on his foot, and the pain was distressing. Sanguineous patches appeared in various parts, and passed off in different periods of time, varying according to the area of extravasation. From careful examinations made on several occasions, both whilst in his ordinary health and during this disturbance of function, I was able to determine a slight decrease in extent of hepatic dulness, and a more decided increase of the splenic. The temperature, taken always between 4 and 5 $P$. M., ranged during eighteen days between 98.2 and 100.4 deg., being highest on the third day. The urine was alkaline; average specific sravity, I.02O; daily quantity, 19 ounces; it contained no albumen, nor sugar. The treatment consisted of a jalap purge; afterwards, the ammonio-citrate of iron; bathing the ankle with water at about $60 \mathrm{deg}$. Fahr.; and moderate support with a bandage. He slowly recovered, and was well on the twentieth day.

The next case is peculiarly interesting, as affording an example of the descent of the diathesis through the female offspring; the female never exhibiting hamorrhagic symptoms, as remarked by Mr. Christopher Ieath

On April I 4 th, I 870 , the husband of the eldest sister of the child, the subject of the last case, brought his child, aged 16 months, to the surgery. The boy had fallen against a chair, and there was considerable extravasation in the cellular tissue of the forehead. The bleeding under the surface continued until the 19 th, by which time the integument was separated from the structures beneath by an interval of at least an inch, for an extent of six inches across. After this date, the swelling s'owly diminished until May 2oth, when it had disappeared. The treatment consisted of aperients, pressure, and fomentations.

On August II th, the boy had again fallen, anc, knocking the upper lip against the teeth, had causcd a lacerated wound of the mucous inembrane. It was bleeding fast. I applied solid nitrate of silver. There was no bleeding for five hours; but it began in the evening, and continued all night until $9 \mathrm{~A} . \mathrm{M}$. on the $19 \mathrm{th}$, when gallic acid caused temporary cessation. A purgative was administered. At 4 P.M., the l:æmorrhage was still unabated. The skin, lips, mouth, and throat, were quite pallid. Two free sanguineous stools had occurred. I applied lint soaked in tincture of perchloride of iron and sprinkled with gallic acid. The bleeding ceased for three-quarters of an hour. At 7 r.M., there were small purple patches about the body-one on the corehead, which might have been caused by the fall, but which was not visible on the previous day. The child was very restless, and intolerant of pressure; he appeared to be sinking. I ordered a teaspoonful of the following mixture to be taken every hour: Tincture of larch, $3 \mathrm{ij}$; spirit of chloroform, $m_{x 1}$; water, 3 iij. On August 20 th, he had passed a restless night. Blood was still oozing. I applied the same styptics as on the previous day. At 4 P.M., the child was stronger the dose of tincture of larch was doubled. At 7 P.M., the hæmorrhage ceased, having continued almost incessantly for fifty-three hours. The medicine was given until the 29 th; but he was not well until the iniddle of September.

\section{SPONTANEOUS INIERSION OF THE UTERUS.*}

\section{By WEBSTER ADAMS, EsQ., Norwich.}

ON the 2 Ist of April last, I was summoned to the house of Mrs. K. to attend her in her accouchement. On arrival at the house, I found the patient a young healthy-looking woman, about 26 years of age, 5 feet 6 inches in height, and dark-complexioned. She complained of pains in the back and other symptoms of labour. I made an examination, and found that the pains were spurious. Consequently, I admiuistered a full dose of tincture of opium, and left directions for the nurse to send if any change occurred. Nothing, however, happened until the morning of the $22 n d$, when I was sent for about 9 A.M., and went immediately. The pains had completely changed; and my patient, I had no doubt at this time, was suffering the natural pains of childbirth. I made another examination now, and found the os uteri soft and dilating; the head presenting. There was no hæmorrhage ; and Mrs. K., to all appearance, was doing well. The frains went on; and, after about an hour and a half, the cliild was expelled. No ergot was administered. The uterus did not contract for some little time after the birth of the child, probably a quarter of an hour. After that time, however, it bcgan slowly to do so; and she complained of a great bearing down, as she termed it, which, upon examining, I believed to

$$
\text { * Read before tie East Anglian Branch. }
$$

be the placenta descending. I accordingly requested her to give way to that feeling, and strain slightly. She did as I directed her; and immediately, without any traction upon the cord, the uterus became inverted, and came down outside the vulva, the placenta being attached to the fundus. No hæemorrhage occurred at this time. Immediately the patient sank into a state of collapse, with cold ashy sweats. She was pulseless, to all appearance, and had a livid countenance and cold extremities. The uterus was immediately, or after the lapse of a few minutes, returned, after removing the placenta, when a gush of blood followed, which was checked by pressing the uterus firmly, and freely applying cold. Stimulants were freely administered, Liebig's essence of beef, brandy, etc. Cold water was copiously employed over the ab. domen, and mustard poultices to the calves of the legs. Unconciousness continued for several hours, when at last consciousness began to return, and the pulse became more full and perceptible, the extremities warmer; and she began to slowly return to her consciousness and feeling, as she expressed herself afterwards.

April 23rd. The pulse was about 9o, soft and compressible. There were no head-symptoms, no pain, nor sickness. She was ordered to continue her beef-tea and wine and water. She had had a few hours' good sleep during the night, and was considered to be doing favourably. I visited her once or twice during the day, and she still continued improving.

April 24th. She had slept pretty well during the night. The pulsc was about 9o, still and soft. She countenance was a little pale; the lips were slightly blue. She told me that she felt better. The stimulants were ordered to be continued.

April 26th. She still continued to improve, and had had relief from the bowels. The tongue looked clean. No febrile symptoms of any moment were present. I ordered her a simple saline mixture, with ten-minim doses of spirit of nitrous ether.

She continued daily to improve, and at the end of a fortnight was able to leave her room. She has been taking a tonic up to the last week - viz., disulphate of quinine and tincture of perchloride of ironfrom which she says she derives much benefit. She has no bearing down, no loss, no pain, no fever, and is daily recovering her usual strength.

This case is the only one which I have had since my experience began in midwifery. I have attended a very large number of cases, and have had several unusual ones; but this is the only case of inversion which I have seen in a practice extending over nine or ten years, averaging threc hundred and fifty to four hundred cases annualiy.

\section{REPORTS}

\section{MEDICAL AND SURGICAL PRACTICE IN THE HOSPITALS OF GREAT BRITAIN.}

\author{
UNIVERSITY COLLEGE HOSPITAL.
}

CASES OF RECURRENT AND MULTIPLE CALCULUS: LITHOTOMY, MEDIAN ANi) LATERAL, AND LITHOTRITY.

(Under the care of Mr. ERIChSEN, Senior Surgeon to University College Hospital, Holme Professor of Clinical Surgery.)

THE three following cases of stone in the bladder are interesting from the fact of their being instances of multiple and recurrent calculus occurring at different ages. To them is added a case of lithotrity occurring at the same time.

CASE I. Lithotomy by Median Operation: Fifty Calculi re'noved: Atony of the Bladder: Cure.-J. D., aged 54, a French master, was admitted on June 27 th, 1870 . He always had good health. Therc was no history of gout, rheumatism, or syphilis. Seven years ago, the patient observed that he passed gravel, and that very often he could not pass urine, or that the stream suddenly stopped. He used to have pain in the testicles, hypogastrium, loins, and penis. The pains in creased on sudden and quick movements. He used to pass urine very frequently during the day and night-sometimes as often as twenty times during the night. During the last seven years the patient had experienced the above symptoms, but they had been more or less intermittent. He said that he had passed about a hundred calculi during that time. He had been under a treatment laid down by the late Dr. Rayer of Paris, consisting mainly in the administration of carbonate of potass.

On admission, the patient appeared stout, but unhealthy. He had a 